\title{
Efek Kepemimpinan, Budaya Organisasi Dan Kepuasan Kerja Terhadap Kinerja
}

\author{
Galih Raspati ${ }^{1}$, Eva Marsusanti ${ }^{2}$, Yuyun Yuniati ${ }^{3}$, Andi Riyanto ${ }^{4}$ \\ ${ }^{1,3}$ STIE Pasim Sukabumi \\ e-mail: 'galih raspati@yahoo.com,3yuyunyuniati37@gmail.com \\ ${ }^{2,4}$ Universitas Bina Sarana Informatika \\ e-mail: 2 eva.emr@bsi.ac.id, 4 andi.iio@bsi.ac.id
}

\begin{abstract}
Abstrak - Penelitian ini dibuat dengan tujuan untuk mendapatkan jawaban secara eksplanatif berkaitan dengan : (1) efek kepemimpinan dengan kinerja , (2) efek budaya organisasi dengan kinerja, dan (3) efek kepuasan kerja dengan kinerja organisasi, (4) efek kepeimpinan, budaya organisasi dan kepuasan kerja untuk memaksimalkan kinerja pada Bank BNI Cabang Sukabumi. Penelitian ini menggunakan desain penelitian kuantitatif yang sifatnya kausalitas. Data kemudian dikumpulkan dengan menggunakan metode angket atau kuisioner yang disebar untuk 76 orang sebagai sampel menggunakan metode sensus, dan menggunakan teknik wawancara. Hasil penelitian kemudian menggunakan analisis data dan pengujian hipotesinya melaui uji $\mathrm{T}$ dan uji $\mathrm{F}$ yang menyatakan bahwa (1) adanya efek searah atau positif antara variabel kepemimpinan dengan variabel kinerja, (2). adanya efek searah atau positif antara budaya organisasi dengan kinerja, (3) adanya efek searah atau positif antara varaibel kepuasan kerja dengan kinerja, (4) adanya efek searah atau positif secara simultan memaksimalkan kinerja. Temuan yang didapatkan dari penelitian ini adalah adanya efek yang secara simultan antara kepemimpinan, budaya organisasi dan kepuasan kerja terhadap kinerja.
\end{abstract}

Kata kunci: kepemimpinan, budaya organisasi, kepuasan kerja dan kinerja organisasi

Abstract - The purpose of this study is to obtain interpretive answers on: (1) the impact of leadership on performance; (2) the impact of organizational culture on performance; (3) the impact of job satisfaction on organizational performance; (4) The influence of leadership, cultural organization and job satisfaction to maximize the performance of BNI Bank Sukabumi branch. This study uses a quantitative research design for causality. Then use census methods and interview techniques to collect data through questionnaires or questionnaire methods, and these data are distributed to 76 people in the form of samples. Then, the research results use data analysis and hypothesis testing through T test and F test, which shows that (1) there is a direct or positive influence between the leadership variable and the performance variable, (2). There is a direct or positive influence between organizational culture and performance, (3) a direct or positive influence between job satisfaction variables and performance, and (4) a direct or positive influence that maximizes performance at the same time. The findings from this study are the simultaneous effects of leadership, organizational culture and job satisfaction on performance.

Keywords: leadership, organizational culture, job satisfaction and organizational performance

\section{PENDAHULUAN}

Dalam era perdagangan bebas dunia di abad 21 memungkinkan terjadi kondisi iklim persaingan yang tinggi disegala aspek yang menuntut perusahaan supaya siap bekerja dengan efektif. Adanya tingkat persaingan yang tinggi serta ditambah dengan adanya pandemi covid-19 saat ini (Luque N \& Salcedo C, 2020) ada empat sektor makro ekonomi yang rentan terdampak yaitu rumah tangga ekonomi, UMKM, korporasi, dan sektor keuangan. Kondisi ini tentunya memberikan pengaruh secara langsung terhadap bank sebagai salah satu korporasi di sektor keuangan agar dapat menjaga serta memaksimalkan sumber daya manusia yang dimilikinya mampu mempertahankan dan meningkatkan kinerja perusahaan tetap profitable.

Bank BNI tercatat sebagai bank nasional terkuat dan terbesar ke-4 di Indonesia kalau dilihat dari jumlah aset, jumlah kredit ataupun jumlah total penyimpanan dana pihak ketiga. BNI dalam memberikan pelayananya sebagai organisasi perusahaan kepada masyarakat di dukung oleh sejumlah anak perusahaan yang secara terpadu mendukung kinerja organisasi termasuk BNI Cabang Sukabumi, di bidang syariah, multifinance, sekuritas, 
life insurance, serta remittance. BNI juga menawarkan service penyimpanan dana ataupun fasilitas pinjaman kredit untuk memenuhi kebutuhan kredit korporasi atau perusahaan, menengah, maupun kecil. Kinerja organisasi anak perusahaan Bank BNI ini telah berhasil memberikan sumbangan $11,6 \%$ dari keuntungan profit yang diperoleh grup BNI pada tahun 2019.

Baik tidaknya penilaian kinerja organisasi pada perusahaan tergantung dari kinerja sumber daya manusia yang secara kolektif menunjukan kinerja organisasi. Kinerja organisasi menurut Farlek dalam (Kenny \& S, 2019) merupakan output aktual organisasi yang diperoleh ketika dibandingkan dengan tujuan dan sasaran dari organisasi. Kinerja sumber daya manusia yang baik hanya dapat diwujudkan oleh kepemimpinan yang baik sehingga kinerja organisasi ditentukan oleh kemampuan pemimpin dalam mengarahkan sumber daya manusia. Kepemimpinan menurut (Surji, 2015) merupakan cara seseorang untuk mempengaruhi pikiran, sikap, dan perilaku orang lain. Kepemimpinan membantu mengarahkan kita ke arah yang sama dan memanfaatkan upaya kita bersama.

Selain itu budaya organisasi dapat menjadi instrumen keunggulan kompetitif yang utama yaitu bila budaya organisasi mendukung strategi organisasi dan dapat menjawab atau mengatasi tantangan lingkungan dengan cepat dan tepat. Budaya organisasi selain berpengaruh terhadap kepuasan kerja juga berpengaruh terhadap kinerja perusahaan.

Faktor lain yang dominan dalam mempengaruhi kinerja adalah kepuasan kerja. Kepuasan kerja karyawan yang tinggi merupakan salah satu indikator efektifitas manajemen, yang berarti bahwa organisasi telah dikelola dengan baik. Abraham Maslow dalam (Liu, Aungsuroch, \& Yunibhand, 2016) menggambarkan kepuasan kerja sebagai pencocokan individu dari kebutuhan seseorang dengan yang dirasakan yang berkaitan dengan potensi pekerjaan untuk memenuhi kebutuhan. Kepuasan kerja didefinisikan sebagai seberapa jauh karyawan puas dengan pekerjaan mereka. Hal ini sering terjadi di mana dua konsep dibahas bersama, karena dikatakan bahwa seseorang puas di tempat kerja karena ada faktor dan kondisi yang memotivasi dia. (Furnham, Eracleous, \& Chamorro-Premuzic, 2009)

Asumsi mengatakan bahwa sistem praktik personal ataupun faktor-faktor sumber daya manusia memiliki dampak langsung pada kinerja organisasi. Maksud dari kinerja adalah tahapan untuk menyelesaikan tugas-tugas tertentu. (Simanjuntak, 2005). Kinerja adalah kemampuan seseorang untuk terlibat dalam kegiatan yang berkontribusi pada pengembangan teknologi inti organisasi. (Santis, Neto, \& Verwaal, 2018). Jadi yang dimaksud dengan kinerja adalah tentang pekerjaan dan pencapaian pekerjaan, dan apa serta bagaimana melakukannya.
Berdasarkan penjelasan serta pendapat teori tersebut diatas, maka peneliti tertarik untuk mengadakan penelitian dengan tema Faktor Kepemimpinan, Budaya Organisasi Dan Kepuasan Kerja Serta Kontribusinya Terhadap Kinerja.

Agar lebih memudahkan dalam melihat alur penelitian, maka dapat digambarkan kerangka pemikiran dari penelitian ini:

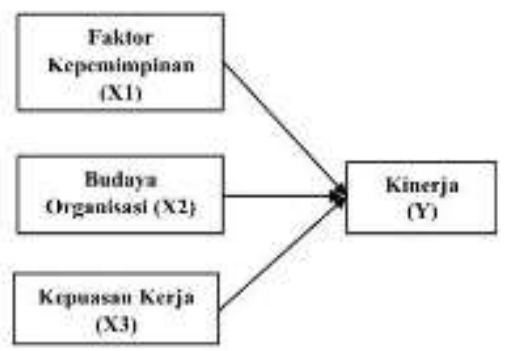

Sumber: Data primer yang diolah, (2020)

Gambar 1. Kerangka Pemikiran

\section{METODE PENELITIAN}

Metode yang dipakai dalam penelitian ini adalah metode deskriptif kuantitatif dengan menekankan penjelasan dan pengambaran masingmasing variabel yang sedang diteliti dengan memakai data yang berbentuk angka kemudian diikuti dengan menjelaskan korelasi atau hubungan kedua variabel tersebut menggunkan uji hipotesis.

Objek dari penelitian ini adalah seluruh pegawai Bank BNI Cabang Sukabumi yang jumlahnya 76 pegawai. Uji instrumen dalam penelitian memakai uji reliabilitas dan validitas. Uji validitas intrumen menggunakan metode uji validitas konstruk. Tiap butir instrumen dikorelasikan dengan menggunakan teknik Product Moment. Uji instrumen dalam penelitian memakai uji reliabilitas dan validitas. Uji validitas intrumen memakai validitas konstruk.

Sebelum menggunakan model regresi linear berganda, data harus terbebas dari asumsi-asumsi klasik, antara lain uji normalitas. Tujuan pengujian asumsi klasik adalah untuk memberikan kepastian bahwa persamaan regresi yang didapatkan memiliki ketepatan dalam estimasi, tidak bias dan konsisten.

Uji normalitas dilakukan untuk memastikan apakah dalam model regresi, variabel residu memiliki distribusi normal atau tidak. Uji normalitas dapat diabaikan ketika jumlah sampel cukup besar (Gio \& Caraka, 2018). Analisis deskriptif atas variabel independen dan dependen dilakukan dengan mengklasifikasikan terhadap jumlah skor responden. Dari jumlah skor jawaban responden yang diperoleh kemudian disusun kriteria penilaian untuk setiap item pernyataan. Peringkat setiap variabel penelitian dapat dilihat dari perbandingan antara skor aktual dengan skor ideal dengan didasarkan pada nilai rata-rata dan dikategorikan dengan rentang skor minimum $=1$ dan 
skor maksimum $=5$, maka lebar skala $\frac{5-1}{5}=0,8$, dengan kategori skala :

Tabel 1.Skala Kategori

\begin{tabular}{|c|c|}
\hline Skala & Keterangan \\
\hline $1,00-1,80$ & Sangat rendah \\
\hline $1,81-2,60$ & Rendah \\
\hline $2,61-3,40$ & Sedang \\
\hline $3,41-4,20$ & Tinggi \\
\hline $4,21-5,00$ & Sangat Tinggi \\
\hline
\end{tabular}

Sumber : Sugiyono, (2014)

Menentukan besarnya derajat hubungan antara variabel dengan menggunakan korelasi pearson dan untuk menghitung masing-masing variabel harus di rangking terlebih dahulu dari terkecil hingga terbesar. Kriteria keeratan antara variabel independen dan variabel dependen digunakan kriteria Champion.

Seberapa besar kontribusi atau peranan variabel $\mathrm{X}$ terhadap $\mathrm{Y}$ dengan menggunakan persamaan koefisien determinan. Besarnya pengaruh antara variabel independen terhadap variabel dependen dapat diketahui dengan menggunakan analisis regresi linier berganda. Untuk melihat hubungan dari kedua jenis variabel yang diteliti yaitu variabel $\mathrm{X}$ dan variabel $\mathrm{Y}$ menggunakan pengujian hipotesis atau uji t. Hasil dari perhitungan statistik uji $\mathrm{t}$ ( $\mathrm{t}_{\text {hitung }}$ ) tersebut selanjutnya dibandingkan dengan $\mathrm{t}_{\text {tabel. }}$. Dengan $\mathrm{dk}=\mathrm{n}-2$ dan tingkat signifikannya yaitu $5 \%(=0,05)$, artinya jika hipotesis 0 (nol) ditolak dengan taraf kepercayaan 95\%, maka kemungkinan hasil dari penarikan kesimpulan mempunyai kebenaran 95\% dan hal ini menunjukkan adanya hubungan (korelasi) yang meyakinkan (signifikan) antara dua variabel tersebut. Untuk mengetahui ditolak atau tidaknya dinyatakan dengan kriteria jika $t_{\text {hitung }}>t_{\text {tabel, }}$ maka $\mathrm{H} 0$ ada di daerah penolakan, berarti Ha diterima artinya terdapat pengaruh antara kepemimpinan, budaya organisasi, dan kepuasan pegawai terhadap kinerja. Kemudian jika $t_{\text {hitung }}<t_{\text {tabel }}$, maka H0 ada di daerah penerimaan, berarti $\mathrm{Ha}$ ditolak, artinya tidak terdapat pengaruh antara kepemimpinan, budaya organisasi dan kepuasan pegawai terhadap kinerja. Analisa hipotesis apakah semua variabel independen yang dimasukkan dalam model mempunyai pengaruh secara bersama-sama terhadap variabel dependen dengan menggunakan uji F dengan kriteria taraf signifikan $\alpha=0,05$ dan kriteria pengujian dimana Ha diterima apabila $\mathrm{p}$ value $<\alpha$ dan Ha ditolak apabila $\mathrm{p}$ value $>\alpha$.

\section{HASIL DAN PEMBAHASAN}

\subsection{Karakteristik Responden}

Karakteristik responden dikelompokkan menurut jenis kelamin, umur, pendidikan dan status pekerjaan. Sesuai dengan dengan hal tersebut uraian mengenai karakteristik responden dalam penelitian ini sebagai berikut:

Tabel 2. Karakteristik Responden Berdasarkan Jenis Kelamin

\begin{tabular}{|c|c|c|}
\hline $\begin{array}{c}\text { Jenis } \\
\text { Kelamin }\end{array}$ & $\begin{array}{c}\text { Jumlah } \\
\text { Responden }\end{array}$ & $\begin{array}{c}\text { Persentase } \\
(\%)\end{array}$ \\
\hline Perempuan & 42 & $55 \%$ \\
\hline Laki-Laki & 34 & $45 \%$ \\
\hline Jumlah & 76 & $100 \%$ \\
\hline
\end{tabular}

Sumber: Data primer yang diolah, (2020)

Berdasarkan tabel di atas, terlihat bahwa responden perempuan sebanyak 42 pegawai atau $55 \%$ dari jumlah sampel 76 pegawai Bank BNI Cabang Sukabumi dan responden laki-laki sebanyak 34 orang atau $45 \%$ dari jumlah sampel sampel 76 pegawai Bank BNI Cabang Sukabumi. Hal ini menunjukkan bahwa dari jumlah sampel yang menjadi responden dalam penelitian ini, responden perempuan lebih banyak dibandingkan responden laki-laki, karena untuk lini terdepan seperti customer service dan teller umumya di dominasi oleh pegawai perempuan.

Tabel 3. Karakteristik Responden Berdasarkan Jenjang Pendidikan

\begin{tabular}{|c|c|c|c|}
\hline No & Pendidikan & Jumlah & Persentase \\
\hline 1 & SMA & 8 & $10,53 \%$ \\
\hline 2 & D III & 10 & $13,15 \%$ \\
\hline 3 & Sarjana & 50 & $65,79 \%$ \\
\hline 4 & Magister & 8 & $10,53 \%$ \\
\hline \multicolumn{2}{r|}{ Total } & 76 & $100 \%$ \\
\hline
\end{tabular}

Sumber: Data primer yang diolah, (2020)

Berdasarkan data dari tabel di atas, terlihat bahwa karakteristik responden berdasarkan pendidikan yang dijadikan sampel dalam penelitian ini yaitu, dengan responden berpendidikan SMA sebanyak 8 orang atau sebanyak 10,53\%, kemudian responden dengan pendidikan DIII yaitu sebanyak 10 orang atau sebanyak $13,15 \%$, Sedangkan responden berpendidikan Sarjana sebanyak 50 orang atau sebanyak 65,79\%. Pegawai yang Magister sebanyak 8 orang atau $10,53 \%$ dari total sampel. Dengan demikian responden terbanyak yang dijadikan sampel dalam penelitian ini adalah responden yang berpendidikan Sarjana.

\subsection{Uji Validitas Instrumen}

Uji validitas dipakai untuk mengukur suatu instrumen apakah mencerminkan arti yang sebenarnya dari konsep yang diteliti, atau untuk mengukur apa yang seharusnya diukur. Pengujian validitas instrumen penelitian ini dengan menggunakan rumus korelasi person (pearson correlation bivariate). Uji validitas Kepemimpinan 
$\left(\mathrm{X}_{1}\right)$ dilakukan terhadap 12 (dua belas) indikator dengan data sampel (n) 76 responden. Kriteria validasi adalah jika koefisien korelasi bernilai $>0,3$, maka butir dinyatakan valid, angka 0,3 merupakan nilai kritis validitas data dengan $\alpha=5 \%$.

Tabel 4. Uji Validitas Instrumen Kepemimpinan (X1)

\begin{tabular}{|c|c|c|c|}
\hline Pernyataan & $\begin{array}{c}\boldsymbol{r} \\
\text { Dengan } \\
\text { Rata- } \\
\text { Rata }\end{array}$ & $\begin{array}{c}\text { Nilai } \\
\text { Kritis }\end{array}$ & Keterangan \\
\hline 1 & 0.739 & 0.3 & Valid \\
\hline 2 & 0.809 & 0.3 & Valid \\
\hline 3 & 0.734 & 0.3 & Valid \\
\hline 4 & 0.778 & 0.3 & Valid \\
\hline 5 & 0.729 & 0.3 & Valid \\
\hline 6 & 0.643 & 0.3 & Valid \\
\hline 7 & 0.554 & 0.3 & Valid \\
\hline 8 & 0.439 & 0.3 & Valid \\
\hline 9 & 0.646 & 0.3 & Valid \\
\hline 10 & 0.801 & 0.3 & Valid \\
\hline 11 & 0.742 & 0.3 & Valid \\
\hline 12 & 0.525 & 0.3 & Valid \\
\hline
\end{tabular}

Sumber: Data primer yang diolah, (2020)

Nilai kritis (r) di ambil dari tabel kritis 0,3 pada $n$ $=76$ dan $\alpha 0,05(5 \%)$

Hasil dari 12 (dua belas) butir pernyataan indikator dinyatakan valid, artinya 12 butir pernyataan tersebut dapat mengukur apa yang hendak di ukur yaitu mengukur variabel X1 Kepemimpinan.

Tabel 5. Uji Validitas Instrumen Budaya Organisasi (X2)

\begin{tabular}{|c|c|c|c|}
\hline Pernyataan & $\begin{array}{c}\boldsymbol{r} \\
\text { Dengan } \\
\text { Rata- } \\
\text { Rata }\end{array}$ & $\begin{array}{c}\text { Nilai } \\
\text { Kritis }\end{array}$ & Keterangan \\
\hline 1 & 0.671 & 0.3 & Valid \\
\hline 2 & 0.703 & 0.3 & Valid \\
\hline 3 & 0.569 & 0.3 & Valid \\
\hline 4 & 0.447 & 0.3 & Valid \\
\hline 5 & 0.732 & 0.3 & Valid \\
\hline 6 & 0.734 & 0.3 & Valid \\
\hline 7 & 0.625 & 0.3 & Valid \\
\hline 8 & 0.790 & 0.3 & Valid \\
\hline 9 & 0.804 & 0.3 & Valid \\
\hline 10 & 0.595 & 0.3 & Valid \\
\hline Suld
\end{tabular}

Sumber: Data primer yang diolah, (2020)

Nilai kritis (r) di ambil dari tabel kritis 0,3 pada $n=76$ dan $\alpha 0,5(5 \%)$

Hasil dari 10 (sepuluh) butir pernyataan indikator dinyatakan valid, artinya 10 butir pernyataan tersebut dapat mengukur apa yang hendak di ukur yaitu mengukur variabel X2 Budaya Organisasi.

Tabel 6. Uji Validitas Instrumen Kepuasan Kerja Karyawan (X3)

\begin{tabular}{|c|c|c|c|}
\hline Pernyataan & $\begin{array}{c}\boldsymbol{r} \\
\text { Dengan } \\
\text { Rata- } \\
\text { Rata }\end{array}$ & $\begin{array}{c}\text { Nilai } \\
\text { Kritis }\end{array}$ & Keterangan \\
\hline 1 & 0.635 & 0.3 & Valid \\
\hline 2 & 0.644 & 0.3 & Valid \\
\hline 3 & 0.640 & 0.3 & Valid \\
\hline 4 & 0.578 & 0.3 & Valid \\
\hline 5 & 0.818 & 0.3 & Valid \\
\hline 6 & 0.366 & 0.3 & Valid \\
\hline 7 & 0.763 & 0.3 & Valid \\
\hline 8 & 0.763 & 0.3 & Valid \\
\hline 9 & 0.805 & 0.3 & Valid \\
\hline 10 & 0.870 & 0.3 & Valid \\
\hline
\end{tabular}

Sumber: Data primer yang diolah, (2020)

Nilai kritis (r) di ambil dari tabel kritis 0,3 pada $n=76$ dan $\alpha 0,05(5 \%)$

Hasil dari 10 (sepuluh) butir pernyataan indikator dinyatakan valid, artinya10 butir pernyataan tersebut dapat mengukur apa yang hendak di ukur yaitu mengukur variabel X3 Kepuasan Kerja.

Tabel 7. Uji Validitas Instrumen Kinerja Organisasi (Y)

\begin{tabular}{|c|c|c|c|}
\hline Pernyataan & $\begin{array}{c}\boldsymbol{r} \\
\text { Dengan } \\
\text { Rata- } \\
\text { Rata }\end{array}$ & $\begin{array}{c}\text { Nilai } \\
\text { Kritis }\end{array}$ & Keterangan \\
\hline 1 & 0.703 & 0.3 & Valid \\
\hline 2 & 0.781 & 0.3 & Valid \\
\hline 3 & 0.647 & 0.3 & Valid \\
\hline 4 & 0.502 & 0.3 & Valid \\
\hline 5 & 0.782 & 0.3 & Valid \\
\hline 6 & 0.675 & 0.3 & Valid \\
\hline 7 & 0.814 & 0.3 & Valid \\
\hline 8 & 0.7844 & 0.3 & Valid \\
\hline 9 & 0.796 & 0.3 & Valid \\
\hline 10 & 0.674 & 0.3 & Valid \\
\hline
\end{tabular}

Sumber: Data primer yang diolah, (2020)

Nilai kritis (r) di ambil dari tabel kritis 0,3 pada $n=76$ dan $\alpha 0,05(5 \%)$

Hasil dari 10 (sepuluh) butir pernyataan indikator dinyatakan valid, artinya10 butir pernyataan tersebut dapat mengukur apa yang hendak di ukur yaitu mengukur variabel $Y$ Kinerja Organisasi.

\subsection{Uji Reliabilitas}

Uji reliabilitas digunakan untuk menguji apakah pernyataan yang diberikan memiliki jawaban yang konsisten sehingga dapat dipercaya bahwa pernyataan tersebut dapat digunakan sebagai alat pengumpul data. 


\begin{tabular}{|c|c|c|}
\hline Variabel & $\mathrm{N}$ & $\begin{array}{c}\text { Cronbach's } \\
\text { Alpha }\end{array}$ \\
\hline Kepemimpinan (X1) & 12 & 0,891 \\
\hline Budaya Organisasi (X2) & 10 & 0,857 \\
\hline Kepuasan Kerja (X3) & 10 & 0,871 \\
\hline Kinerja Organisasi (Y) & 10 & 0.895 \\
\hline
\end{tabular}

Sumber: Data primer yang diolah, (2020)

Nilai reliabilitas X1 Kepemimpinan dari 12 item pernyataan diperoleh nilai Alpha Cronbach's $(\alpha)$ sebesar 0,891 atau reliabel dengan $\alpha>0,8$, yang berarti instrumen variabel $\mathrm{X} 1$ Kepemimpinan sangat realiabel artinya dapat dipercaya sebagai alat untuk mengumpulkan data atau jawaban responden konsisten dan seragam. Nilai reliabilitas Budaya Organisasi dari 10 item pernyataan diperoleh nilai Alpha Cronbach's $(\alpha)$ sebesar 0,857 atau sangat reliabel dengan $\alpha>0,8$ yang berarti instrumen variabel Budaya Organisasi dapat dipercaya sebagai alat untuk mengumpulkan data atau jawaban responden konsisten dan seragam. Nilai reliabilitas variable X3 Kepuasan Kerja dari 10 item pernyataan diperoleh nilai Alpha Cronbach's $(\alpha)$ sebesar 0,871 atau reliabel dengan $\alpha>0,8$ yang berarti instrumen variabel Kepuasan Kerja sangat reliabel dan dapat dipercaya sebagai alat untuk mengumpulkan data atau jawaban responden konsisten dan seragam. Nilai realibilitas Y Kinerja Organisasi dari 10 item pernyataan diperoleh nilai Alpha Cronbach's $(\alpha)$ sebesar 0,895 atau sangat reliabel dengan $\alpha>0,8$ yang berarti instrumen variabel Y sangat reliabel dan dapat dipercaya sebagai alat untuk mengumpulkan data atau jawaban responden konsisten dan seragam.

\subsection{Uji Normalitas}

Tabel 9. Hasil Uji Normalitas

\begin{tabular}{|c|c|}
\hline Keterangan & Nilai Residu \\
\hline N & 76 \\
\hline .Sig & 0,200 \\
\hline
\end{tabular}

Sumber: Data primer yang diolah, (2020)

Hasil uji normalitas melalui One-Sample Kolmogorov-Smirnov Test menunjukkan nilai asymp. Sig. (2-tailed) diperoleh nilai signifikansi sebesar $0,200(0,200>0,05)$, maka berdasarkan NPar 1sample K-S dapat katakan bahwa untuk data yang digunakan berdistribusi normal.

\subsection{Analisa Koefisien Korelasi}

Seberapa besar efek dinamis Kepemimpinan, Budaya Organisasi dan Kepuasan Kerja untuk dapat memaksimalkan atau meningkatkan Kinerja Organisasi, maka data-data yang telah didapatkan selama penelitian akan di analisis dengan metode Korelasi Pearson.
Tabel 10. Hasil Analisis Koefisien Korelasi Pearson

\begin{tabular}{|c|c|c|c|}
\hline Variabel & $\begin{array}{c}\text { Kepimpinan } \\
\text { (X1) }\end{array}$ & $\begin{array}{c}\text { Budaya } \\
\text { Organi } \\
\text { sasi (X2) }\end{array}$ & $\begin{array}{c}\text { Kepuasan } \\
\text { Kerja } \\
\text { Karyawan } \\
\text { (X3) }\end{array}$ \\
\hline $\begin{array}{c}\text { Kinerja } \\
\text { Organisasi } \\
\text { (Y) }\end{array}$ & 0.745 & 0.808 & 0.675 \\
\hline \multicolumn{2}{|c|}{ Sumber: Data primer yang di olah, (2020) }
\end{tabular}

Hasil analisis dengan uji korelasi pearson terhadap nilai korelasi Kepemimpinan (X1) dengan Kinerja Organisasi $(\mathrm{Y})$ sebesar $\mathrm{r}=0,745$ yang berarti berada di antara nilai +/- 0,51 - 0,75 maka hubungannya cukup kuat dan searah. Sifat hubungan positif, yang artinya jika Kepemimpinan meningkat maka Kinerja Organisasi akan meningkat pula. Nilai korelasi Budaya Organisasi (X2) dengan Kinerja Organisasi ( $\mathrm{Y}$ ) sebesar $\mathrm{r}=0.808$ yang berarti berada di antara nilai +/- 0,76 - 1,00, maka memiliki hubungan sangat kuat dan searah. Sifat hubungan positif yang artinya jika Budaya Organisasi meningkat maka Kinerja Organisasi akan meningkat pula.Hasil analisa dengan uji korelasi pearson terhadap nilai korelasi Kepuasan Kerja (X3) dengan Kinerja Organisasi (Y) sebesar $r=0,675$ yang berarti berada di antara nilai +/- 0,51 - 0,75 maka hubungannya cukup kuat dan searah. Sifat hubungan positif, yang artinya jika Kepuasan Kerja meningkat maka Kinerja Organisasi akan meningkat pula.

\subsection{Analisa Koefisien Determinasi dan Regresi Linier Berganda}

Koefisien determinasi bertujuan untuk mengetahui besarnya kontribusi Kepemimpinan, Budaya Organisasi dan Kepuasan Kerja terhadap Kinerja Organisasi. Analisis regresi linear berganda digunakan dengan maksud untuk mengetahui sejauh mana Kepemimpinan, Budaya Organisasi dan Kepuasan Kerja dapat memaksimalkan Kinerja Organisasi.

Tabel 11. Hasil Analis Regresi Linier Berganda

\begin{tabular}{|c|c|c|}
\cline { 2 - 3 } \multicolumn{1}{c|}{} & $\begin{array}{c}\text { Unstandardized } \\
\text { Coefficients }\end{array}$ & $\begin{array}{c}\text { Standardized } \\
\text { Coefficients }\end{array}$ \\
\hline $\begin{array}{c}\text { Kepemimpinan } \\
\text { (X1) }\end{array}$ & 0,237 & 0,229 \\
\hline $\begin{array}{c}\text { Budaya } \\
\text { Organisasi (X2) }\end{array}$ & 0,625 & 0,584 \\
\hline $\begin{array}{c}\text { Kepuasan Kerja } \\
\text { (X3) }\end{array}$ & $0, .58$ & 0,54 \\
\hline $\begin{array}{c}\text { Konstanta }=0,228 \\
\mathrm{R}=0.824\end{array}$ & \multicolumn{2}{|c|}{} \\
\hline
\end{tabular}

Sumber: Data primer yang diolah, (2020)

Hasil dari regresi linier berganda diperoleh nilai konstanta sebesar 0,228 sedangkan nilai Kepemimpinan sebesar 0,237 dan 0,625 sehingga persamaan regresi berganda dapat dituliskan $\mathrm{Y}=$ 
$0,228+0,229 \times 0,237+0,584 \times 0,625+0,54 \times .0 .58$ Persamaan regresi tersebut dapat diterjemahkan sebagai berikut, konstanta sebesar 0,228 menyatakan bahwa jika Kepemimpinan (X1), Budaya Organisasi (X2) dan Kepuasan Kerja (X3) tidak ada kenaikan atau sama dengan nilai 0 , maka besarnya Kinerja Organisasi (Y) juga sama sebesar 0,228. Nilai koefisien regresi variabel Kepemimpinan (X1) sebesar 0,237 dan bertanda positif, artinya jika variabel Kepemimpinan meningkat sebesar 1 point,maka akan menyebabkan nilai Kinerja Organisasi meningkat sebesar 0,237 poin. Ini menunjukan bahwa Kepemimpinan memiliki hubungan searah dengan Kinerja Organisasi. Nilai koefisien regresi variabel Budaya Organisasi (X2) sebesar 0,625 dan bertanda positif, artinya jika variabel Budaya Organisasi (X2) naik sebesar 1 point,- maka akan menyebabkan nilai Kinerja Organisasi naik sebesar 0,625 point. Nilai koefisien regresi variabel Kepuasan Kerja Karyawan (X3) sebesar 0,58 dan bertanda positif, artinya jika variabel Kepuasan Kerja (X3) naik sebesar 1 point maka akan menyebabkan nilai Kinerja Organisasi naik sebesar 0,58 poin. Ini menunjukan bahwa variabel Kepemimpinan, Budaya Organisasi dan Kepuasan Kerja memiliki hubungan searah atau positif dengan variabel Kinerja Organisasi.

\subsection{Uji t}

Uji t digunakan untuk mengetahui apakah dalam model regresi variabel independen secara parsial berpengaruh signifikan terhadap variabel dependen atau tidak.

Hasil uji $\mathrm{t}$ efek hubungan dinamis antara Kepemimpinan (X1) terhadap Kinerja Organisasi (Y) dapat diketahui bahwa variabel Kepemimpinan memiliki signifikansi $0,00<0,05$, atau $t_{\text {hitung }}>t_{\text {tabel }}$ dengan $\mathrm{n}-\mathrm{k}(76-4)$, sehingga 2,651>1,993 dengan taraf signifikansi 0,05 maka dapat disimpulkan bahwa H0 ditolak dan $\mathrm{H} 1$ diterima. Ini artinya bahwa terdapat efek yang signifikan dari Kepemimpinan (X1) terhadap Kinerga Organisasi (Y).

Hasil uji t efek hubungan dinamis antara Budaya Organisasi (X2) terhadap Kinerga Organisasi (Y) diketahui bahwa variabel Budaya Organisasi memiliki signifikansi $0,00>0,05$, atau $t_{\text {hitung }}>t_{\text {tabel }}$, sehingga $5,017>1,993$ maka dapat disimpulkan maka $\mathrm{H} 0$ ditolak dan $\mathrm{H} 2$ diterima, maka dapat disimpulkan bahwa $\mathrm{H} 0$ ditolak dan $\mathrm{H} 2$ diterima. Ini artinya bahwa terdapat efek yang signifikan dari Budaya Organisasi (X2) terhadap Kinerja Organisasi (Y).

Hasil uji t efek hubungan dinamis antara Kepuasan Kerja Karyawan (X3) terhadap Kinerja Organisasi (Y) diketahui bahwa variabel Kepuasan Kerja Karyawan memiliki signifikansi 0,00 > 0,05, atau $t_{\text {hitung }}>t_{\text {tabel}}$, sehingga $2,437>1,993$ maka dapat disimpulkan maka $\mathrm{H} 0$ ditolak dan $\mathrm{H} 2$ diterima, maka dapat disimpulkan bahwa H0 ditolak dan H3 diterima. Ini artinya bahwa terdapat efek hubungan dinamis yang signifikan dari Kepuasan Kerja Karyawan (X3) terhadap Kinerja Organisasi (Y).

\subsection{Uji F}

Uji $F$ bertujuan untuk menguji efek hubungan dinamis antara Kepemimpinan $\left(\mathrm{X}_{1}\right)$, Budaya Organisasi $\left(\mathrm{X}_{2}\right)$ dan Kepauasan Kerja Karyawan $\left(\mathrm{X}_{3}\right)$ secara simultan (bersama-sama) untuk meningkatkan Kinerja Organisasi (Y).

Tabel 12. Hasil Uji F

\begin{tabular}{|c|c|c|}
\hline & $\mathrm{F}$ & Sig \\
\hline Regresi & 50,695 & 0,000 \\
\hline \multicolumn{3}{|c|}{ Signifikansi $=5 \%(0,05)$} \\
\hline
\end{tabular}

Berdasarkan tabel di atas, dapat diketahui bahwa signifikansi $0,000<0,05$ dan $\mathrm{F}_{\text {hitung }}$ (F-stat) sebesar 50,695, Nilai ini dibandingkan dengan nilai $F_{\text {tabel }}$ pada tabel distribusi $F$, dengan demikian $\alpha=$ $0,05, \mathrm{df}=(\mathrm{k} ; \mathrm{n}-\mathrm{k})=(3 ; 76-3)=(3 ; 73)$. Kemudian untuk pengujian dua sisi (two-tailed) di peroleh nilai $F_{\text {tabel }}$ sebesar 3,20. Diketahui bahwa $F_{\text {hitung }}(50,695)>$ $F_{\text {tabel }}(2,73)$ atau $F_{\text {hitung }}>F_{\text {tabel }}$, sehingga $\mathrm{H} 0$ ditolak (H1 diterima). Artinya terdapat hubungan dinamis yang secara simultan dan signifikan dari variabel Kepemimpinan (X1), Budaya Organisasi (X2) dan Kepauasan Kerja Karyawan (X3) untuk memaksimalkan dan meningkatkan Kinerja Organisasi (Y).

Hasil penelitian ini sesuai dengan penelitian yang menyatakan gaya kepemimpinan dan budaya organisasi memiliki dampak signifikan dan positif terhadap kinerja organisasi secara tidak langsung melalui kepuasan kerja sebagai variabel intervening, dimana gaya kepemimpinan ternyata pengaruhnya lebih baik dan kuat untuk meningkatkan kinerja organisasi yang secara tidak langsung di dukung oleh kepuasan kerja. (Ariyawan \& Rivai, 2018).

Berikutnya dari riset yang mempelajari tentang pengaruh gaya kepemimpinan terhadap kepuasan kerja, komitmen dan kemauan untuk mengundurkan diri yang hasil risetnya menunjukkan bahwa kepemimpinan mempengaruhi kinerja kerja secara positif dan signifikan. (Ali, Ali, Ahsan, Rahman, \& Kakakhel, 2014)

Menurut penelitian (Eliyana \& Ma'arif, 2019) pengelolaan kerja karyawan dapat melalui gaya kepemimpinan transformasional yang memiliki pengaruh besar terhadap komitmen organisasi dan kepuasan kerja karyawan.

\section{KESIMPULAN}

Kesimpulan yang dapat diambil bahwa secara parsial Kepemimpinan (X1) berdampak signifikan terhadap Kinerja Organisasi (Y) Bank BNI Cabang Sukabumi, artinya setiap kebijakan 
kepemimpinan yang menekankan pada orientasi tugas, orientasi hubungan dan orientasi efektifitas maka secara otomatis akan memiliki hubungan dinamis dan dapat meningkatkan kinerja organisasi Bank BNI Cabang Sukabumi. Kemudian variabel Budaya Organisasi (X2) secara parsial berdampak signifikan terhadap Kinerja Organisasi (Y) Bank BNI Cabang Sukabumi artinya bila selalu ditanamkan nilai inovasi, pengambilan resiko, perhatian rinci, orientasi pada hasil kerja, orientasi pada nasabah, orientasi tim, keagresifan dan stabillitas maka akan mampu memaksimalkan atau meningkatkan kinerja organisasi. Variabel Kepuasan Kerja (X3) berdampak signifikan terhadap Kinerja Organisasi (Y) artinya bila tingkat kepuasan kerja lebih ditekankan kepada aspek.pembayaran gaji tepat waktu, karakteristik pekerjaan yang jelas, relasi rekan kerja yang harmonis, promosi pekerjaan secara inovatif, dan supervisi yang kontiunitas. Variabel Kepemimpinan (X1) Budaya Organisasi (X2) dan Kepuasan Kerja (X3) secara simultan dan signifikan memiliki hubungan dinamis yang kuat untuk dapat memaksimalkan atau meningkatkan Kinerja Organisasi (Y) sehingga secara otomatis akan makin meningkatkan profesionalitas Bank BNI Cabang Sukabumi.

Rekomendasi untuk penelitian yang akan datang agar dapat mengembangkan pada faktor kepemimpinan organisasi yang lebih luas agar dapat membuat penelitian dilakukan lebih baik, lebih spesifik dan komprehensif.

\section{REFERENSI}

Ali, N., Ali, S., Ahsan, A., Rahman, W., \& Kakakhel, S. J. (2014). Effects of Leadership styles on job satisfaction, organizational citizenship behavior, commitment and turnover intention (empirical study of private sector schools' teachers). Life Sci J, 11(4), 175-183.

Ariyawan, Y. W., \& Rivai, A. (2018). Influence Of Leadership Style And Organizational Culture On Organizational Performance Through Job Satisfaction In PT Telekomunikasi Indonesia Tbk. The International Journal of Engineering and Science (IJES), (2010), 21-37. https://doi.org/10.9790/1813-0710032137

Eliyana, A., \& Ma'arif, S. (2019). Job satisfaction and organizational commitment effect in the transformational leadership towards employee performance | Elsevier Enhanced Reader.
European Research on Management and Business Economics, 25(3), 144-150. Retrieved from https://reader.elsevier.com/reader/sd/pii/S2444 883418300196?token=FC263694411E75D1B 09AEE23177BCFB36D58ACC2C078A6CD0 3930612B1254E085F0D1BC85717AE3C94A 107AC031C17B6

Furnham, A., Eracleous, A., \& Chamorro-Premuzic, T. (2009). Personality, motivation and job satisfaction: Hertzberg meets the Big Five. Journal of Managerial Psychology, 24(8), 765779. https://doi.org/10.1108/02683940910996789

Gio, P. U., \& Caraka, R. E. (2018). Pedoman Dasar Mengolah Data Dengan Program Aplikasi Statistika Statcal. Medan, Indonesia: USU Press.

Kenny, S., \& S, V. K. (2019). Munich Personal RePEc Archive Employee productivity and organizational performance: A theoretical perspective, (93294), 0-10.

Liu, Y., Aungsuroch, Y., \& Yunibhand, J. (2016). Job satisfaction in nursing: A concept analysis study. International Nursing Review, 63(1), 84-91. https://doi.org/10.1111/inr.12215

Luque N \& Salcedo C. (2020). COVID-19 Y LAS UNIDADES DE CUIDADOS INTENSIVOS EN EL PERÚ. REVISTA DE MEDICINA INTENSIVA Y CUIDADOS CRÍTICOS, 13(1), 5 .

Santis, A. S., Neto, M. T. R., \& Verwaal, E. (2018). Does cultural capital matter for individual job performance? A large-scale survey of the impact of cultural, social and psychological capital on individual performance in Brazil. International Journal of Productivity and Performance Management, 67(8), 1352-1370.

Simanjuntak, P. J. (2005). Manajemen dan evaluasi kinerja. Jakarta: FE UI.

Sugiyono. (2014). Metode Penelitian Kuantitatif Kualitatif dan $R \& D$. Bandung: CV. Alfabeta.

Surji, K. (2015). Understanding Leadership and Factors that Influence Leaders' Effectiveness. European Journal of Business and Management, $\quad 7(33), \quad 3$. https://doi.org/10.7176/ejbm/7-33-2015-03 